\title{
Reverberações das experiências extramurais no ensino da Odontologia
}

\section{Reverberations of extramural experiences in Dentistry teaching}

Patrícia Ferreira de Sousa Viana ${ }^{1}$, Shara Jane Holanda Costa Adad², José Ivo dos Santos Pedrosa ${ }^{3}$

${ }^{1}$ Núcleo de Estudos em Saúde Pública da Universidade Federal do Piauí (UFPI), Campus Ministro Petrônio Portella - Teresina (PI), Brasil.

${ }^{2}$ Programa de Pós-Graduação em Educação da UFPI, Campus Ministro Petrônio Portella - Teresina (PI), Brasil.

${ }^{3}$ Coordenação do Curso de Medicina da UFPI, Campus Parnaíba - Parnaíba (PI), Brasil.

\section{RESUMO}

Introdução: O perfil do cirurgião-dentista, eminentemente técnico, resulta de uma formação voltada à clínica dentária - cosmética e descontextualizada. Nesse cenário, surgem as Diretrizes Curriculares Nacionais, as quais trazem em seu bojo, dentre outras recomendações, a ampliação dos espaços de ensino-aprendizagem com base em cenários reais de prática, possibilitando experiências concretas na realidade social. Objetivo: Identificar, nas oportunidades pedagógicas propostas pelo curso, aspectos capazes de influenciar transformações no processo de ensino-aprendizagem em Odontologia. Métodos: Trata-se de um estudo qualitativo, descritivo e com abordagem sociopoética para a produção e análise dos dados. Participaram do estudo graduandos em Odontologia inseridos em atividades pedagógicas extramurais. Quatro oficinas sociopoéticas foram realizadas e serviram de instrumento para o desenvolvimento de narrativas sobre as experiências de ensino-aprendizagem. Resultados: Três linhas de pensamentos emergiram a partir da análise sociopoética dos dados: tempo para viver as experiências de ensino-aprendizado; coexistência de novas e velhas abordagens pedagógicas e desafios decorrentes dos projetos de mudanças. Conclusão: A despeito dos desafios enfrentados, admite-se a importância dos extramuros, curriculares ou não, no ensino odontológico. Tais vivências levam os alunos a compartilharem o espaço das práticas no Sistema Único de Saúde com outros atores; assim, ao transitarem pelo mundo do trabalho e do ensino, eles criam um modelo mental de seu processo de ensino-aprendizagem, influenciado pelos referenciais teóricos, pelas oportunidades de vivências no campo das práticas e pelos interesses individuais. Esses elementos interferem e ampliam a percepção de si e do mundo, na medida em que percorrem o caminho da formação, construindo um trajeto singular.

Palavras-chave: ensino; aprendizagem; educação em saúde; odontologia.

\section{ABSTRACT}

Introduction: A dentist's profile, which is predominantly technical, results from a training focused on dental, cosmetics and decontextualized clinics. Hence, the Brazilian National Curriculum Guidelines arouse, comprising, among other recommendations, the expansion of teaching and learning spaces based on real settings of practice that enable concrete experiences in the social reality. Objective: To identify, in the pedagogical opportunities proposed for the course, aspects that may influence changes on the teaching-learning process in Dentistry. Methods: This is a qualitative and descriptive study, based on socio-poetics approach to produce and analyze data Undergraduates in Dentistry inserted in extramural pedagogical activities took part in the study. Four socio-poetics workshops were conducted, and they were used as an instrument to develop narratives on the teaching-learning experiences. Results: Three lines of thought emerged from the socio-poetics data analysis: time to live the teaching-learning experiences; coexistence of old and new pedagogical approaches; and challenges arising from change projects. Conclusion: Despite the faced challenges, the importance of curricular or non-curricular extramural is assumed in Dentistry teaching. These experiences lead students to share spaces of practices in the Brazilian Unified Health System with other actors; thus, by moving in the world of work and teaching, students create a mental model of the teaching-learning process, which is influenced by the theoretical framework, by opportunities of experiences in the field of practice, and by personal interests. Such elements interfere and increase the perception of themselves and of the world, since they advance in the training process, building a singular way.

Keywords: teaching; learning; health education; dentistry.

Recebido em: 18/08/2015

Revisado em: 27/09/2015

Aprovado em: 27/09/2015

Autor para correspondência: Patrícia Ferreira de Sousa Viana - Avenida Campos Sales, 1.925 - Centro - CEP: $64000-300$ - Teresina (PI), Brasil -

E-mail: patyviana@gmail.com

Fonte de financiamento: Coordenação de Aperfeiçoamento de Pessoal de Nível Superior (CAPES).

Conflito de interesses: nada a declarar. 


\section{INTRODUÇÃO}

O ensino odontológico no Brasil surgiu dentro das escolas médicas na Bahia e no Rio de Janeiro ${ }^{1}$ e sua desvinculação, em termos legais, deu-se a partir de decretos que aprovaram os regimentos das escolas de medicina e as diretrizes específicas para as faculdades de Odontologia ${ }^{2}$.

A separação entre práticas odontológicas e médicas foi o que tornou possível o surgimento da Odontologia enquanto profissão. Essa autonomia, inclusive de prescindir dos conhecimentos e procedimentos inerentes à clínica médica, guiou o seu embasamento científico. Muitos fatores influenciaram e definiram, ao longo do tempo, a formação e o perfil profissional atual, os quais variam desde as práticas dentárias dos barbeiros até a formação dos cirurgiões-médicos; passando pela necessidade de organizar e articular sistemas de profissionalização, regulação e ensino das práticas de cura; pelas mudanças em relação à compreensão das doenças bucais e das pesquisas científicas na área².

O perfil do cirurgião-dentista é eminentemente técnico, refletindo uma formação voltada para a clínica dentária - cosmética e descontextualizada ${ }^{3}$. Assumindo-se, portanto, que o ensino odontológico se encontra ainda elitizado, fragmentado, centrado na cura das doenças e com tendência à especialização precoce ${ }^{4}$. Nesse contexto, foi desenvolvido um movimento que propõe mudanças nos paradigmas da formação profissional, marcada teórica e metodologicamente pelas Diretrizes Curriculares Nacionais (DCN) para os cursos de Odontologia, no início de $2002^{5}$.

As DCN sugerem, prioritariamente, alterações na organização dos cursos a fim de proporcionar aos educandos novas formas de se instruir, sob a perspectiva do aprender pela vivência, pela sensibilidade e pelo contato com o outro, buscando a formação de profissionais capazes de reconhecer as necessidades do indivíduo e, sobretudo, garantir a integralidade, a qualidade e a humanização do cuidado em saúde 5 . Contudo, sem abrir mão da excelência técnica e dos fundamentos teórico-científicos, tendo como cenários de ensino-aprendizagem o Sistema Único de Saúde (SUS) e as experiências concretas na realidade social ${ }^{6}$.

Além disso, as DCN propõem que os cursos de graduação em Odontologia tenham um projeto pedagógico construído coletivamente, tendo o aluno como sujeito da aprendizagem e o professor como mediador desse processo, buscando a formação integral e adequada do estudante por intermédio da articulação entre o ensino, a pesquisa e a extensão/assistência. Também recomendam a utilização de, no mínimo, $20 \%$ da carga horária total do curso para o desenvolvimento de estágios curriculares sob a supervisão docente ${ }^{5}$.

A Associação Brasileira de Ensino Odontológico (ABENO) definiu o atual conceito de estágio curricular supervisionado para Odontologia, reconhecendo-o como um dispositivo que materializa a articulação entre ensino-pesquisa-extensão e favorece a inserção do aluno no contexto socioeconômico de seu futuro campo de atuação profissional ${ }^{7}$.

A importância das experiências extramurais é ratificada pela Lei 11.788 , de 25 de setembro de 2008, ou lei do estágio, definindo-o em seu art. $1^{\circ}$ como "o ato educativo escolar supervisionado, desenvolvido no ambiente de trabalho, que visa à preparação para o trabalho produtivo de educandos". Além disso, esclarece, no parágrafo $2^{\circ}$, que o estágio busca o "aprendizado de competências próprias da atividade profissional e à contextualização curricular, objetivando o desenvolvimento do educando para a vida cidadã e para o trabalho", integrando o ensino e o serviço ${ }^{8}$.

Campos et al. ${ }^{9}$ propõem um sistema de incentivos (político, técnico e financeiro) às instituições formadoras para que adotem práticas de integração ensino-pesquisa-extensão sob a égide da integralidade e da interdisciplinaridade na formação dos profissionais de saúde. Nesse sentido, os Ministérios da Saúde e Educação criaram programas de reorientação da formação em saúde como o Pró e o PET-Saúde, para estimular produção de conhecimentos e prestação de serviços com ênfase na atenção básica, de acordo com as necessidades individuais e coletivas da população ${ }^{10}$.

O problema central deste estudo é o papel das vivências extramurais, curriculares, ou não, dos alunos do curso de Odontologia da Universidade Federal do Piauí (UFPI), como fator desencadeador da reorientação do ensino acadêmico. Teve-se como objetivo identificar, nas oportunidades pedagógicas propostas pelo curso, aspectos capazes de influenciar transformações no processo de ensino-aprendizagem em Odontologia.

\section{MÉTODOS}

Este trabalho é parte integrante de uma pesquisa mais abrangente intitulada Educação e Saúde: bases epistemológicas e metodológicas da formação de profissionais para o SUS, em execução pelo Núcleo de Estudos em Saúde Pública (NESP), respondendo ao edital 24/2010 da Coordenação de Aperfeiçoamento de Pessoal de Nível Superior (CAPES), com a pretensão de cartografar a formação dos profissionais da área de saúde graduados pela UFPI ${ }^{11}$.

Trata-se de um estudo qualitativo e descritivo, com a utilização do método sociopoético para produção e análise dos dados, tendo como campo de investigação o curso de Odontologia da UFPI. A população de estudo incluiu discentes do referido curso que estivessem inseridos em cenários de prática extramurais, no momento da produção dos dados da pesquisa. Consideraram-se como vivências extramurais, para efeitos de produção e análise dos dados neste estudo, as inserções no SUS por intermédio das disciplinas de Odontologia em Saúde Coletiva I e II (quarto e sexto períodos do curso), os Estágios Supervisionados II, III e IV (sétimo, oitavo e nono períodos, respectivamente) e o grupo PET-Saúde Atenção Primária.

A população de estudo foi composta por oito alunos inseridos em atividades extramurais curriculares, sendo que cinco deles também participavam do PET-Saúde. É válido destacar que, em pesquisas qualitativas, o foco da investigação está voltado ao adensamento e à abrangência da compreensão do fenômeno estudado, portanto o critério para definição da "amostra" não é numérico ${ }^{12}$. No estudo, aprovado conforme o Certificado de Apresentação para Apreciação 
Ética (CAAE) no 34015914.2.0000.5214, os alunos adotaram nomes de árvores da flora piauiense como pseudônimos, atendendo aos critérios de confidencialidade e proteção da imagem dos participantes.

Quatro oficinas sociopoéticas foram realizadas e serviram de instrumento para a produção do conteúdo empírico. O método sociopoético é aplicado na produção e análise de dados em pesquisas qualitativas. Etimologicamente, o termo sociopoética vem do latim socius - aquilo que é coletivo - e do grego poiésis - criação portanto, caracteriza-se pela construção coletiva do conhecimento ${ }^{13}$. Trata-se de um dispositivo de pesquisa que revela "os problemas que mobilizam os grupos sociais e promove a criação de novos problemas ou de novas maneiras de problematizar a vida"14.

A sociopoética emprega técnicas criativas para a produção dos dados, promovendo outras formas de comunicar e produzir sentido, por meio de signos ou metáforas que remetem ao objeto da pesquisa. Neste caso, o modo elegido para a produção de metáforas e, portanto, dos dados, foi a árvore dos saberes, inspirada na Árvore do Conhecimento de Gauthier ${ }^{15}$. Para as produções artísticas, foram utilizados materiais diversos como tinta guache de cores variadas, pincéis de pelo, canetas esferográficas e papel texturizado.

Os estudantes fizeram relatos orais sobre as suas produções e a vivência sociopoética, criando narrativas potentes do encontro entre as experiências extramurais e os afetos (emoções, aprendizados ou escolhas) que atravessam o processo de formação. Os procedimentos analíticos empregados no tratamento das narrativas foram: categorização, análise classificatória e estudos transversais, culminando com o reagrupamento das categorias que emergiram do conteúdo empírico produzido.

\section{RESULTADOS}

Os resultados serão exibidos em três linhas de pensamentos: tempo para viver as experiências de ensino-aprendizado (tempo influenciando o trajeto pedagógico na formação em Odontologia); coexistência de novas e velhas abordagens pedagógicas e desafios decorrentes dos projetos de mudanças.

A primeira linha de pensamento diz respeito à construção de um currículo que oportunize vivências de relevâncias técnica e social, sustentado pela flexibilização e integração curricular em modelos pedagógicos mais interativos, na adoção das metodologias de ensino-aprendizagem centradas no aluno e no professor como facilitador do processo de construção de conhecimento ${ }^{16}$. Entretanto, segundo relatos dos alunos, as expectativas de um currículo mais flexível são frustradas pelas grades que o aprisionam, restringindo as possibilidades de novas experiências de ensino-aprendizagem.

A segunda ideia aponta para a convivência salutar entre os novos dispositivos pedagógicos e as práticas mais tradicionais de ensino, em uma perspectiva solidária e de complementaridade. Em tempos da valorização de experiências fora dos muros da universidade, a sala de aula aparece como local possível de transformação.

As ferramentas pedagógicas utilizadas nos estágios supervisionados extramuros do curso de Odontologia da UFPI colocam-se como um dispositivo indutor de mudança, no que se refere ao modelo de ensino-aprendizagem proposto pelas DCN, bem como a experiência PET-Saúde, vivenciada pela primeira vez nos territórios da UFPI e do curso de Odontologia.

Por fim, a terceira linha de pensamento apresenta os desafios impostos pelos movimentos de mudança paradigmática, tais como a violência urbana interferindo nos cenários de prática e o alheamento do corpo docente responsável pelas disciplinas ditas clínicas ou profissionalizantes em relação às atividades em saúde coletiva.

\section{DISCUSSÃo}

\section{O tempo influenciando o trajeto pedagógico na formação em Odontologia}

A flexibilização curricular surgiu no cenário de reformulação do ensino superior, em contraposição ao currículo mínimo, e diz respeito à garantia de tempo livre, amplo o suficiente para permitir ao discente incorporar outras formas de ensino-aprendizagem e formação social ${ }^{17}$. As DCN para os cursos de graduação em Odontologia sugerem que a estrutura curricular contemple mecanismos que permitam ao estudante desenvolver ou aprimorar vocações, interesses e potenciais específicos, sem prejuízos à obtenção de conhecimentos essenciais ao exercício da profissão ${ }^{18}$.

Desse modo, a UFPI vem se adequando, pelo menos normativamente, às proposições das DCN, expressando em seu Plano de Desenvolvimento Institucional a intenção de garantir a flexibilidade e a criatividade na elaboração de propostas curriculares dos cursos. Além disso, sugere uma formação acadêmica que ultrapasse os limites da sala de aula, articulando-se com diferentes dimensões da realidade locorregional ${ }^{17}$.

Para experimentar o desconhecido e se expor aos riscos inerentes ao andar na vida, no mundo real dos serviços de saúde, é preciso muito mais do que o armazenamento de informações, pois, de acordo com Serres ${ }^{19}$, mais vale uma cabeça bem-constituída a um saber acumulado, tendo em vista que a agregação de saberes já se encontra sistematizada nos livros.

$\mathrm{Na}$ dialética entre a apropriação de conhecimentos profundos e a perícia de empregá-los corretamente, Perrenoud ${ }^{20}$ alerta que ambas são necessárias para a construção de um profissional competente e habilidoso no exercício de sua prática. Em uma conversa com Foucault, Deleuze afirmou que "nenhuma teoria pode se desenvolver sem encontrar uma espécie de muro e é preciso a prática para atravessar o muro"21.

Entretanto, o que se percebe é a priorização do acúmulo de informações em detrimento da experiência vivida, de forma sistemática e excessiva. Não se trata de abandonar as ferramentas intelectuais, mas de garantir a sinergia entre teoria e prática.

A escassez de tempo livre para viver experiências fora dos muros da UFPI denota que, mesmo após a reformulação do Projeto Pedagógico de Curso (PPC), a rigidez do currículo de Odontologia ainda persiste. Não por acaso, a metáfora currículo-grade reflete 
os sentimentos dos discentes em relação ao aprisionamento de outras possibilidades de experiências do ensino-aprendizagem, para além dos componentes curriculares.

O obstáculo currículo-grade da formação em Odontologia é a grade curricular que a gente tem. Que a grade realmente prende a gente aqui dentro. É uma grade de verdade. A gente não tem tanto espaço assim, a gente tenta inserir o PET de um jeito ou de outro nessa grade curricular para que a gente possa ir aos cenários. E é difícil achar tempo para isso [...] (Carnaúba).

A gente não tem conhecimento dessas opções que têm por fora. A gente está presa aqui dentro. A gente tem um tempo, mínimo, mínimo, mínimo, mínimo para você fazer tudo aquilo e tem que se virar. E mesmo se tivesse [conhecimento dessas opções], a gente não tem tempo para agarrar todas essas oportunidades. É complicado [...] (Acácia).

Segundo Capozzolo et al. ${ }^{22}$, não se deve confundir experiência com simples exposição à prática, é necessário atribuir um sentido $\mathrm{e}$ submeter o aluno a um processo de produção das subjetividades e instrumentalizá-lo para agir e pensar de forma crítica e criativa os problemas e as soluções possíveis, pois o que está em jogo não é a construção de convicções e conhecimentos sólidos, mas a tessitura do cognitivo, dos sentidos e dos afetos.

\section{Coexistência de velhas e novas abordagens pedagógicas}

O trabalho de Bulgarelli et al. ${ }^{23}$, realizado com alunos do curso de Odontologia da Universidade Federal do Rio Grande do Sul (UFGRS), apresenta a percepção dos graduandos em relação aos estágios supervisionados no SUS, a qual está ligada à importância do professor engajado e comprometido com a proposta do estágio, à compreensão de que o elo entre teoria e prática se inicia na sala de aula, passando pela clínica com o professor, e construindo-se cotidianamente ao longo de sua formação acadêmica, bem como durante os estágios.

Eu acho que é lá [na sala de aula] que o PET acontece. Lá foi onde o PET aconteceu para mim e mudou minha forma de ver as coisas [...] (Aroeira).

A valorização dos cenários reais de prática, imprescindíveis para a formação de um profissional sensível aos determinantes do processo saúde-doença, coexiste com o encontro singular aluno-professor, que acontece na sala de aula e também ocorre nos corredores da universidade, nos e-mails das madrugadas insones e nas redes sociais. É em tal cumplicidade que o aprendiz encontra suportes emocional e teórico (indispensáveis) para dar os seus primeiros passos no território das práticas.

Assim, torna-se fundamental a reflexão sobre o papel do docente enquanto orientador e facilitador do processo de formação, na medida em que é também no cotidiano da sala de aula que se expressa um modo de ensinar comprometido com o SUS, por meio de práticas pedagógicas participativas que fogem da rotina e repetição ${ }^{24}$.

O professor não deve ser o único responsável pelo sistema de ensino e aprendizagem do educando. Esse papel deve ser compartilhado com os profissionais do serviço. Portanto, cabe ao conjunto professor-preceptor-aluno desenvolver atividades de pesquisa, ensino e extensão, tendo a atenção primária à saúde (APS) como local privilegiado de formação, explorando as situações do cotidiano para a produção de conhecimento e educação permanente dos profissionais do serviço, na busca da consolidação do SUS ${ }^{25}$.

Nesse contexto, iluminado especialmente pelo PET-Saúde, ganha destaque a figura do preceptor, o qual desempenha um papel essencial no processo de formação dos alunos, no desenvolvimento de competências para a vida profissional, incluindo conhecimentos, habilidades e atitudes que atendam às diversas demandas dos serviços de saúde ${ }^{26}$.

[...] ele [o preceptor X] simplesmente me mostrou a relação do SUS com a comunidade [...] (Ipê-Amarelo).

Os preceptores são os aliados, porque a gente chega lá de paraquedas, eles estão inseridos na equipe deles e eles têm que arrumar um meio de inserir a gente também (Carnaúba).

É necessário investir na formação didático-pedagógica dos preceptores para a adequada condução do processo de ensino-aprendizagem nos serviços, em consonância com o planejamento e os objetivos do curso $^{27}$. Freire ${ }^{28}$, em sua pedagogia de autonomia, ensina que "como professor, não me é possível ajudar o educando a superar sua ignorância se não supero permanentemente a minha. Não posso ensinar o que não sei”.

Para ilustrar o uso de novas tecnologias pedagógicas no processo de ensino-aprendizagem nos estágios extramuros, apresenta-se um trecho do relato de experiência dos estudantes do quarto período em suas vivências fora dos muros da UFPI, retirados do blog criado pelos alunos ${ }^{29}$ :

O saldo final foi o de uma manhã iluminada que proporcionou a todos uma lição de vida que os livros e as aulas não proporcionam, uma lição de que toda pessoa é acima de tudo um ser humano com uma história de vida única e que não só merece, como precisa do nosso respeito e atenção, sobretudo aqueles que possuem determinadas deficiências e transtornos [...].

Outro exemplo de metodologia participativa é a utilização da rede social Instagram, uma ferramenta on-line que permite o compartilhamento instantâneo da vivência com os demais alunos, professores e preceptores, em uma espécie de diário eletrônico, possibilitando a interação e a troca 
de experiências em ato, nos diversos cenários de prática ${ }^{30}$. Essas experiências pedagógicas atuam no sentido de conferir autonomia e emancipação tanto acerca do processo de ensino-aprendizagem, quanto das relações estabelecidas entre aluno-profissional-comunidade ${ }^{31}$.

\section{Desafios decorrentes dos projetos de mudanças}

A inserção de alunos no cotidiano dos serviços de saúde não é uma tarefa fácil. As dificuldades vão desde o mapeamento dos cenários de prática, passando pela adesão de preceptores ao compartilhamento de responsabilidades pedagógicas na formação dos alunos, até problemas relacionados à segurança dos estudantes no deslocamento de suas casas ou da universidade às Unidades de Saúde.

A violência urbana é um tema que atravessa e influencia negativamente o andar na vida e vem pautando, inclusive, a tomada de decisões institucionais em relação ao processo de formação em saúde, como mostra o trabalho de Capozzolo et al. ${ }^{32}$ sobre a implantação do eixo referente à integração ensino-serviço-comunidade da Universidade Federal de São Paulo (Unifesp), campus Baixada Santista. Eles testemunharam que a inserção de alunos nos cenários de prática é cercada por entraves, tensões e "jogo de forças institucionais". Entretanto, o maior desafio apresentado pelos discentes e docentes estava atrelado à violência presente nas áreas de vulnerabilidade social - cenários de prática discente.

A experiência da Unifesp com a inserção dos alunos no SUS converge com os relatos dos alunos do curso de Odontologia da UFPI em relação ao estágio extramuros na clínica odontológica de atenção básica ampliada (ABA), localizada em uma área periférica da região sul de Teresina.

Agora está tendo até uma confusão. Tem a questão dos docentes, porque mesmo eles tendo que ir para serviços como da Clínica $\mathrm{ABA}$, que eles têm que ir pra auxiliar a gente, eles não querem [...] porque lá é perigoso (Babaçu).

Um aluno da minha sala [...] já chegou a ver um rapaz apontando o revólver na cabeça do outro. E a gente chegou a dizer que não ia fazer estágio na Clínica ABA (Jambo).

A Unifesp solucionou a crise por meio de fóruns de debate sobre a inserção dos alunos nos cenários de prática, concluindo que, para além da questão violência, o envolvimento de docentes mais experientes e com afinidades em relação às atividades na comunidade foi decisivo para a superação dos problemas. No caso da UFPI, o conflito foi gerenciado pela disponibilização de um segurança e um veículo para transportar os alunos da universidade até a clínica do extramuros.
A gente pediu um carro para levar e trazer a gente e um segurança, porque é o mínimo que eles podiam fornecer. Aí, colocaram um carro à disposição [...] (Jambo).

Evidencia-se que a mudança de paradigma na formação em saúde é um processo que requer diálogo entre os corpos docente e discente, os gestores do setor de saúde e a universidade; capacitação docente para o enfrentamento dos desafios presentes nos cenários de prática; apoio institucional para a superação de crises, além da valorização docente e dos profissionais de saúde.

Outro entrave relatado pelos alunos da UFPI é quanto ao alheamento do corpo docente responsável pelas disciplinas ditas clínicas ou profissionalizantes em relação às atividades em saúde coletiva, adiando o movimento de institucionalização e consolidação da integração ensino-serviço-comunidade. Na visão de Morita e Kriger $^{33}$, as atividades pedagógicas "extramurais sempre dependeram mais da voluntariedade dos professores que as coordenavam do que do apoio institucional e da participação do quadro docente como um todo".

Os demais professores têm uma dificuldade com essa parte de saúde coletiva. Tem uma certa rejeição, não sei. É sempre essa guerra, que é muito visível aqui na Odontologia. A saúde coletiva é como se fosse coisa de pobre, uma coisa fraca que tem não tem futuro. A ida da gente ao SUS e, especificamente para a Clínica ABA [clínica extramuros], é como se fosse uma prerrogativa só da saúde coletiva (Acerola).

Diante disso, Araújo $^{34}$ propõe a recusa da noção cada vez mais estereotipada da formação de dois tipos de profissionais: um de segunda classe, ao se propor uma formação para os profissionais do SUS; e outro, mais competente, para as clínicas especializadas do mercado privado a fim de capacitar profissionais diferentes daqueles que irão atuar na APS.

Admite-se que, mesmo diante de esforços e investimentos em novas formas de ensinar e aprender, é preciso estar ciente da incompletude do humano, em todos os sentidos. O reconhecimento do inacabado necessariamente implica em um permanente processo de busca. Dessa forma, conhecer, aprender e ensinar não se esgotam. A educação nesse aspecto apropria a concepção de formação como um processo, o sujeito vai construindo sua capacidade crítica e reflexiva, fazendo escolhas à medida que vai desenvolvendo a sua autonomia.

[...] Quem quiser mesmo seguir esse caminho de conhecer o SUS, eu acho que vai muito além do PET. Tem que ir além da formação acadêmica, porque é um saber que é contínuo. Eu acho que não acaba no momento que eu posso fazer uma especialização, que eu acabe esse projeto. Eu acho que têm muitas coisas que podem ser 
vistas e que esse caminho é muito, muito longo e que está muito longe de eu chegar nessa árvore [...] (Ipê-Amarelo).

[...] Eu me sinto muito no começo ainda, apesar de estar no sexto período, eu me sinto uma caloura praticamente. Não me sinto preparada diante de tudo que eu acho que deveria estar preparada já no sexto período (Acácia).

É lícito reconhecer a importância dos extramuros, curriculares ou não, no ensino de Odontologia. A partir dessas vivências, os alunos dividem com outros atores o espaço de práticas no SUS. Assim, ao transitarem pelo mundo de trabalho e ensino, eles criam um modelo mental do seu processo de ensino-aprendizagem, que é influenciado pelos referenciais teóricos, pelas oportunidades de vivências no campo das práticas e pelos interesses individuais. Tais elementos interferem e ampliam a percepção de si e do mundo, na medida em que percorrem o caminho da formação, construindo um trajeto singular.

\section{AGRADECIMENTOS}

Aos alunos do curso de Odontologia da UFPI que, gentilmente, reservaram um tempo em suas agendas para a participação nas oficinas sociopoéticas.

\section{REFERÊNCIAS}

1. Morita MC, Haddad AE, Araújo ME. Perfil atual e tendências do cirurgião-dentista brasileiro. Maringá: Dental Press; 2010.

2. Warmling CM, Marzola NR, Botazzo C. Da autonomia da boca: práticas curriculares e identidade profissional na emergência do ensino brasileiro da odontologia. Hist Cienc Saúde-Manguinhos. 2012;19(1):181-95. http://dx.doi.org/10.1590/S0104-59702012000100010

3. Emmerich A, Castiel LD. Lagarto e a rosa no asfalto: odontologia dos desejos e das vaidades. In: Botazzo C. De lagartos e rosas. Rio de Janeiro: Fiocruz; 2013.

4. Moura MS, Ferro FE, Cunha NL, Sousa Nétto OB, Lima MD, Moura LF. Saúde bucal na Estratégia de Saúde da Família em um colegiado gestor regional do estado do Piauí. Ciênc Saúde Coletiva. 2013;18(2):471-80. http://dx.doi.org/10.1590/S1413-81232013000200018

5. Brasil. Ministério da Educação. Parecer CNE/CES n 1.300/2001 Diário Oficial da União. Brasília; 2001; p. 25.

6. Silveira JL. Diretrizes curriculares nacionais para os cursos de graduação em odontologia: historicidade, legalidade e legitimidade. Pesq Bras Odontoped Clin Integr. 2004;4(2):151-6.

7. Associação Brasileira de Ensino Odontológico (ABENO). Diretrizes da ABENO para a definição do estágio supervisionado nos cursos de Odontologia. Rev ABENO. 2002;2(1):31.

8. Brasil. Presidência da República: Casa Civil. Subchefia para Assuntos Jurídicos. Lei 11. 788, de 25 de setembro de 2008. Brasília; 2008.

9. Campos FE, Ferreira JR, Feuerwerker L, Sena RR, Campos $\mathrm{JJ}$, Cordeiro $\mathrm{H}$, et al. Caminhos para aproximar a formação de profissionais de saúde das necessidades da Atenção Básica. Rev Bras Educ Med. 2001;25(2):52-9.

10. Brasil. Ministério da Saúde. Ministério da Educação. Programa Nacional de Reorientação da Formação Profissional em Saúde Pró-Saúde: objetivos, implementação e desenvolvimento potencial. Brasília: Ministério da Saúde; 2007.

11. Pedrosa JIS, Lustosa AF. Trilhas da interdisciplinaridade: a experiência da instituição do projeto ensino em saúde na UFPI. In: Barros Júnior FO, Almeida MG, Barbosa VR, Figueirêdo EB. Ensino na Saúde: outras palavras. Brasília: Verbis; 2012. p. 11-39.

12. Minayo MC. O desafio do conhecimento: pesquisa qualitativa em saúde. 12a ed. São Paulo: Hucitec; 2010.

13. Santos MC. Páginas Sociopoéticas: deslizando nas ideias e nos conceitos de jovens sobre leitura Tese (Mestrado) - Universidade Federal do Piauí, Teresina; 2013.
14. Adad SJ. A sociopoética e os cinco princípios: a filosofia dos corpos misturados na pesquisa em educação. In: Adad SJ, Petit SH, Santos I, Gauthier J. Tudo que não inventamos é falso: dispositivos artísticos para pesquisar, ensinar e aprender com a sociopoética. Fortaleza: UECE; 2014. p. 41-59.

15. Gauthier J. O oco do vento: metodologia da pesquisa sociopoética e estudos transculturais. Curitiba: CRV; 2012.

16. Feuerwerker LC, Sena RR. Contribuição ao movimento de mudança na formação profissional em saúde: uma avaliação das experiências UNI. Interface. 2002;6(10):37-50 http://dx.doi.org/10.1590/S1414-32832002000100004

17. Ministério da Educação. Universidade Federal do Piauí. Plano de Desenvolvimento Institucional (PDI): 2015-2019. Teresina: EDUFPI; 2015

18. Conselho Nacional de Educação. Câmara de Educação Superior. Resolução CNE/CES 3/2002. Diário Oficial da União, Brasília; 2002. p. 10.

19. Serres M. Polegarzinha: uma nova forma de viver em harmonia, de pensar as instituições, de ser e de saber. Rio de Janeiro: Bertrand Brasil; 2013.

20. Perrenoud P. Construir as competências desde a escola. Porto Alegre: Artes Médicas Sul; 1999.

21. Foucault M, Deleuze G. Os intelectuais e o poder. In: Foucault M. Microfísica do poder. 25ª ed. São Paulo: Graal; 2012.

22. Capozzolo AA, Inbrizi JM, Liberman F, Mendes R. Formação descentrada na experiência. In: Capozzolo AA, Casetto SJ, Henz AO. Clínica Comum: itinerários de uma formação em saúde. São Paulo: Hucitec; 2013. p. 124-50.

23. Bulgarelli AF, Souza KR, Baumgarten A, Souza JM, Rosing CK, Toassi RF. Formação em saúde com vivência no Sistema Único de Saúde (SUS): percepções de estudantes do curso de Odontologia da Universidade Federal do Rio Grande do Sul (UFRGS), Brasil. Interface. 2014;18(49):351-62. http://dx.doi.org/10.1590/1807-57622013.0583

24, Universidade Federal do Rio Grande do Sul. Curso de Especialização em Docência na Saúde. O protagonismo docente diante dos compromissos da formação com o SUS. Porto Alegre: Educa Saúde; 2014.

25. Tavares CM. Análise crítica de uma experiência de integração do estágio de enfermagem em saúde mental ao Sistema Único de Saúde. Esc Anna Nery R Enferm. 2006;10(4):740-7. 
26. Barreto VH, Monteiro RO, Magalhães GS, Almeida RC, Souza LN. Papel do preceptor da atenção primária em saúde na formação da graduação e pós-graduação da Universidade Federal de Pernambuco - um termo de referência. Rev Bras Educ Med. 2011:35(4):578-83.

http://dx.doi.org/10.1590/S0100-55022011000400019

27. Trajman A, Assunção N, Venturi M, Tobias D, Toschi W, Bran V. A preceptoria na rede básica da Secretaria Municipal de Saúde do Rio de Janeiro: opinião dos profissionais de Saúde. Rev Bras Educ Med. 2009;33(1):24-32.

http://dx.doi.org/10.1590/S0100-55022009000100004

28. Freire P. Pedagogia da autonomia: saberes necessários à prática educativa. São Paulo: Paz e Terra; 1996.

29. Abreu ML, Carvalho RM. Pelos trilhos da Odontologia. Disponível em: http://pelostrilhosdaodonto.blogspot.com.br/. Acesso em: 28 set. 2015.
30. Centro de Ciências da Saúde. Departamento de Patologia e Clínica Odontológica. Manual de Orientação dos Estágios Supervisionados Extramuros II, III e IV. Teresina: Universidade Federal do Piauí; 2014

31. Pedrosa JI. Iniciação às práticas de saúde: bricolagem na seleção de conteúdos. Rev Bras Educ Med. 2013;37(3):408-17. http://dx.doi.org/10.1590/S0100-55022013000300013

32. Capozzolo AA, Casetto SJ, Henz AO, Kinoshita RT. Movimentos de constituição do eixo trabalho em saúde. In: Capozzolo AA, Casetto SJ, Henz AO. Clínica comum: itinerários de uma formação em saúde. São Paulo: Hucitec; 2013. p. 69-111.

33. Morita MC, Kriger L. Mudanças nos cursos de Odontologia e a interação com o SUS. Rev Abeno. 2004;4(1):17-21.

34. Araújo ME. Palavras e silêncios na educação superior em odontologia. Ciênc Saúde Coletiva. 2006;11(1):179-82. http://dx.doi.org/10.1590/S1413-81232006000100026 